\title{
Electrochemical Synthesis of Magnesium Hexaboride by Molten Salt Technique
}

\author{
S. Angappan, ${ }^{1}$ N. Kalaiselvi, ${ }^{2}$ R. Sudha, ${ }^{1}$ and A. Visuvasam ${ }^{1}$ \\ ${ }^{1}$ CSIR-Central Electrochemical Research Institute, Karaikudi 630006, India \\ ${ }^{2}$ Department of Physics, Selvam Arts and Science College, Namakkal 637003, India \\ Correspondence should be addressed to S. Angappan; angs67@gmail.com
}

Received 24 March 2014; Revised 23 May 2014; Accepted 26 May 2014; Published 31 August 2014

Academic Editor: Sarkarainadar Balamurugan

Copyright (c) 2014 S. Angappan et al. This is an open access article distributed under the Creative Commons Attribution License, which permits unrestricted use, distribution, and reproduction in any medium, provided the original work is properly cited.

\begin{abstract}
The present work reports electrochemical synthesis of $\mathrm{MgB}_{6}$ from molten salts using the precursor consists of $\mathrm{LiF}-\mathrm{B}_{2} \mathrm{O}_{3}-\mathrm{MgCl}_{2}$. An attempt has been made to synthesize metastable phase $\mathrm{MgB}_{6}$ crystal by electrolysis method. DTA/TGA studies were made to determine the eutectic point of the melt and it was found to be around $900^{\circ} \mathrm{C}$. The electrolysis was performed at $900^{\circ} \mathrm{C}$ under argon atmosphere, at current density of $1.5 \mathrm{~A} / \mathrm{cm}^{2}$. The electrodeposited crystals were examined using XRD, SEM, and XPS. From the above studies, the electrochemical synthesis method for hypothetical $\mathrm{MgB}_{6}$ from chloro-oxy-fluoride molten salt system is provided. Mechanism for the formation of magnesium hexaboride is discussed.
\end{abstract}

\section{Introduction}

Rare earth and alkaline earth metal borides belong to the group of nonoxide type metal-like compounds and have high melting point, high chemical stability, stable specific resistance, low expansion coefficient at certain temperature ranges, diverse magnetic orders, and high neutron absorbability $[1,2]$. They have possessed excellent corrosion and wear resistance, chemical inertness, and thermal shock resistance more than that of oxide ceramics $[3,4]$. The alkaline earth hexaborides were long thought to be simple polar semiconductors with single particle gap energy of several tenths of an $\mathrm{eV}$ and the energy gap is narrow as well as indirect band gap $\left(\Delta E_{g}=0.0150\right.$ Ry $)$.

Electrochemical synthesis of $\mathrm{Mg}-\mathrm{B}$ system from molten salts is an economic feasible and environmental friendly way for the preparation of different binary phases [5]. Particularly, the $\mathrm{Mg}-\mathrm{B}$ system was reported early $[6,7]$ to contain five phases, whereas Serebryakova [8] reported only four phases. Borides can exist as a wide range of compositions and display structural features, which depends strongly on the metal and boron ratio. Markowsky et al. proposed formation of three phases with higher $\mathrm{B}$ content as the result of thermal decomposition of $\mathrm{MgB}_{2}$ : (1) $\mathrm{MgB}_{6}$, (2) unknown, and (3) $\mathrm{MgB}_{12}$ [9]. However, Duhart reexamined these data and claimed that phase 1 corresponds to $\mathrm{MgB}_{4}$ and phase 2 to $\mathrm{MgB}_{6}$ and the formation of $\mathrm{MgB}_{12}$ (phase 3) was not confirmed [10]. $\mathrm{MgB}_{6}$ and $\mathrm{MgB}_{4}$ do not exist as individual phases and obviously are metastable with rather long equilibration times. According to Somsonov et al. [11], $\mathrm{Mg}-\mathrm{B}$ system has four stable borides: $\mathrm{MgB}_{2}, \mathrm{MgB}_{4}, \mathrm{MgB}_{6}$, and $\mathrm{MgB}_{12} . \mathrm{Mg}-\mathrm{B}$ system contains the phases of $\mathrm{MgB}_{2}, \mathrm{MgB}_{4}, \mathrm{MgB}_{6}, \mathrm{MgB}_{12}$, and $\mathrm{Mg}_{2} \mathrm{~B}_{14}$. So the $\mathrm{Mg}-\mathrm{B}$ system is known as multiphase system. The aim of the present work is to study whether the thermodynamically unstable $\mathrm{MgB}_{6}[12,13]$ could be prepared as thermally stable compound by electrochemical synthesis method.

\section{Experimental Procedure}

The mixture of the salts $\mathrm{LiF}(12.95 \mathrm{~mol} \%), \mathrm{B}_{2} \mathrm{O}_{3}(22.27 \mathrm{~mol} \%)$, and $\mathrm{MgCl}_{2}$ (17.14 mol\%) (analytical grade from Merck, India) was taken as an electrolyte in high-density graphite crucible and acts as an electrolyte cell as well as anode for the electrolytic process. The Molybdenum rod of $1 \mathrm{~cm}$ diameter fitted to a stainless steel rod is used as cathode. The crucible was filled with the stoichiometric quantities of electrolyte salts, which were dried at $500^{\circ} \mathrm{C}$ under argon atmosphere. The whole assembly was placed in an inconel reactor, which was kept in an electrical heating furnace with thermocouple. The 


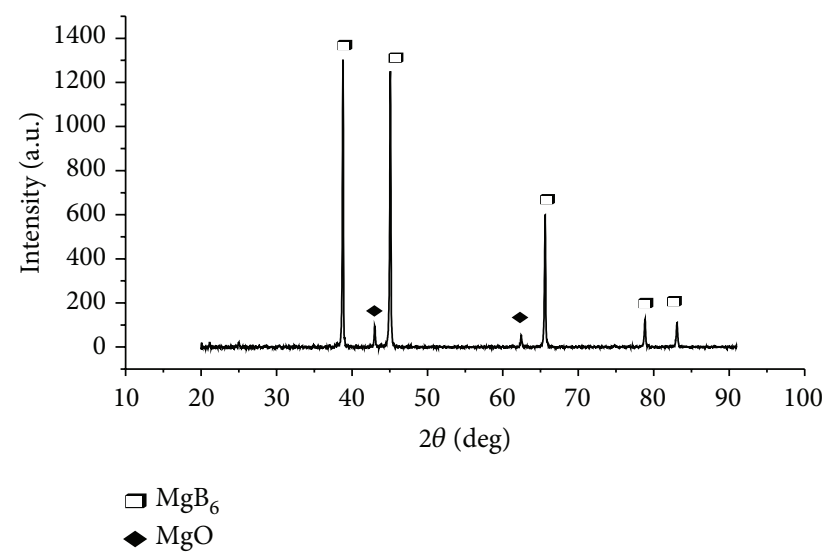

Figure 1: XRD pattern for $\mathrm{MgB}_{6}$.

experimental setup for the electrosynthesis of magnesium hexaboride is described elsewhere [14-17]. Then the salts were melted slowly under a continuous flow of argon gas. The melt was equilibrated at $900^{\circ} \mathrm{C}$ for one hour before proceeding electrolysis [15-17]. The bath was preelectrolyzed at $2.0 \mathrm{~V}$ for one hour to remove the impurities and moisture prior to electrolysis. The cathode was centrally positioned at the electrolytic cell. Experiment was carried out at current density of $1.5 \mathrm{~A} / \mathrm{cm}^{2}$ with the molar ratio of $\mathrm{Mg}: \mathrm{B}$ as $1: 6$. After 5 hours of electrolysis the cathode was removed and the deposit was cooled in atmosphere. The deposit was then scraped off and the electrolyte adhering to it was leached with warm $5 \% \mathrm{HCl}$ solution. Finally washing was done with distilled water for several times, the weight of the deposit was determined, and the nature of the powder was analyzed.

The phase formation and the structural details of the synthesized compound were characterized by X-ray powder diffraction (XRD) using $\mathrm{CuK} \alpha(\lambda=1.541 \AA)$ radiation with $2 \theta$ value range of 20 to 90 using PAnalytical X'pert powder diffractometer. Differential thermal analysis and thermogravimetric analysis (TGA/DTA) of the reaction mixture was done using Rigaku Thermal-Plus TG 8120 with heating speed $20^{\circ} \mathrm{C} / \mathrm{min}$ in a flow of air. The Fourier transform infrared (FTIR) spectra were recorded in the range of 400 to $4000 \mathrm{~cm}^{-1}$ using Perkin Elmer UK Paragon-500 spectrometer. Scanning electron microscopy (SEM) was employed for the morphological studies using JEOL JSM 3.5 CF Japan make model. UV Visible Spectrophotometer was employed for the absorbance study using JASCO Model 7800 UV Visible Spectrophotometer. Studying the binding energy of boron and magnesium was done using X-ray photoelectron spectroscopy Thermo Scientific UK Multilab 2000.

\section{Results and Discussion}

Figure 1 presents the powder XRD pattern of the $\mathrm{MgB}_{6}$ synthesized by molten salt technique. The lattice constant value $a=4.114 \AA$ is determined from the XRD data and is well matched with the reported value $(a=4.115 \AA)$ [18-20] for $\mathrm{MgB}_{6}$ (JCPDS data card number 08-0421) existing in body centered cubic crystal structure (the space group Pm3m)

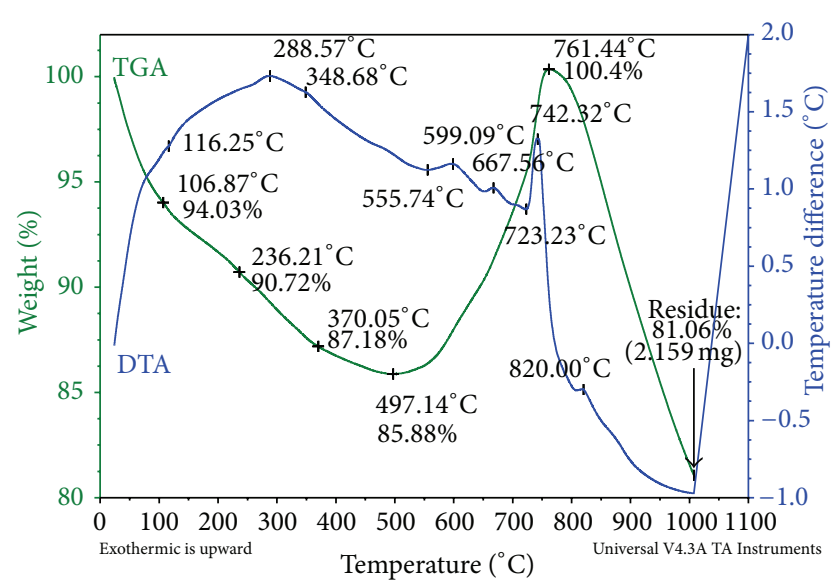

Figure 2: TG/DTA curve for $\mathrm{MgB}_{6}$.

[20]. But indexing the plans for $\mathrm{MgB}_{6}$ is difficult because the information on its lattice parameters and structure system is not available in 08-0421. The main building blocks of the $\mathrm{MgB}_{6}$ structure are $\mathrm{B}_{6}$ octahedra. Other than $\mathrm{MgB}_{6}$ some additional traces of $\mathrm{MgO}$ are also present at $2 \theta=43$ and $62.5^{\circ}$ due to the partial oxidation of $\mathrm{Mg}$ [21]. The crystalline size is found to be $42 \mathrm{~nm}$ calculated by using Debye-Scherrer equation as follows:

$$
D=\frac{k \lambda}{\beta \cos \theta},
$$

where $k$ is the Scherrer constant usually taken as $0.9, \lambda$ is the wavelength characteristics of the $\mathrm{Cu}-\mathrm{K} \alpha$ radiation $(\lambda=$ $1.5406 \AA$ ), $\beta$ is the full width at half-maximum (FWHM) in radiations, $\theta$ is the reflecting angle, and $D$ is the crystal size.

The TGA/DTA curve for the reaction mixture is shown in Figure 2. The figure showed that the eutectic point of the melt is found to be $820^{\circ} \mathrm{C}$. The melt temperature is kept approximately $80^{\circ} \mathrm{C}$ higher than the eutectic point to reduce the melt viscosity. The $\mathrm{LiF}$ is used to increase the fluidity and electrical conductivity of the melt. Its decomposition potential is more cathodic than any other salts chosen. A gradual weight loss observed up to $497^{\circ} \mathrm{C}$ may be due to the removal of moisture and inbound water associated with the salts. The weight gain which is observed up to $761^{\circ} \mathrm{C}$ from $497^{\circ} \mathrm{C}$, due to $\mathrm{B}_{2} \mathrm{O}_{3}$, begins to turn into liquid (melting point $450^{\circ} \mathrm{C}$ ) in the heating process. These reactants whether in the liquid or gaseous state play a crucial role in determining the shape of the final product. Further, this weight gain is mainly due to the oxidation of the reactants (2) [22, 23]. $\mathrm{MgCl}_{2}$ stretches excess $\mathrm{Mg}$ and also increases the electrical conductivity of the melt. This excess $\mathrm{Mg}$ combines with $\mathrm{O}$ forming $\mathrm{MgO}$ (from residual $\mathrm{B}_{2} \mathrm{O}_{3}$ ). The formation of $2 \mathrm{MgCl}_{2} \cdot 3 \mathrm{~B}_{2} \mathrm{O}_{3}$ is due to the solid-state reaction between residual $\mathrm{B}_{2} \mathrm{O}_{3}$ and $\mathrm{MgCl}_{2}$, turn into molten state (melting point of $\mathrm{MgCl}_{2}: 708^{\circ} \mathrm{C}$ ) is confirmed by an exothermic peak at $761^{\circ} \mathrm{C}$. Finally, the reactants can be oxidized thoroughly at $761^{\circ} \mathrm{C}$ [24]. Further weight loss observed up to $1000^{\circ} \mathrm{C}$ is responsible for the transformation of the reactants into desired product. In the DTA curve, a sharp exothermic spike 


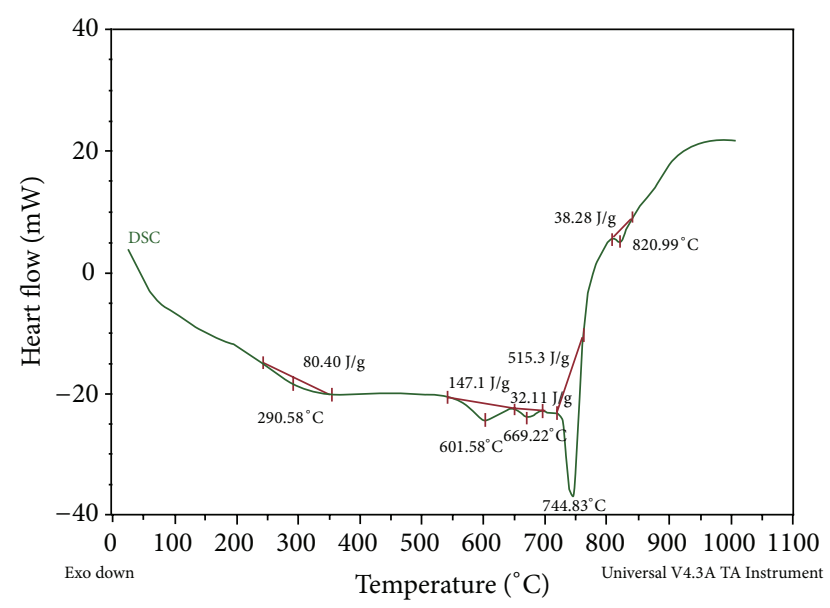

Figure 3: DSC curve for $\mathrm{MgB}_{6}$.

is observed at $742^{\circ} \mathrm{C}$ which may also be verified by confirming this process. This is gratuitous to the DSC curve (Figure 3 ) at $745^{\circ} \mathrm{C}$; a sharp exothermic spine is observed that the heat of decomposition of salts is about $513.3 \mathrm{~J} / \mathrm{g}$.

The reaction was carried out for $\mathrm{MgB}_{6}$ in $\mathrm{MgCl}_{2}-\mathrm{B}_{2} \mathrm{O}_{3}-$ $\mathrm{LiF}$ system; the main chemical reactions are

$$
\begin{gathered}
2 \mathrm{MgCl}_{2}+3 \mathrm{~B}_{2} \mathrm{O}_{3} \longrightarrow 2 \mathrm{MgCl}_{2} \cdot 3 \mathrm{~B}_{2} \mathrm{O}_{3} \\
2 \mathrm{MgCl}_{2} \cdot 3 \mathrm{~B}_{2} \mathrm{O}_{3} \longrightarrow \mathrm{MgB}_{6}+\mathrm{MgO}+4 \mathrm{O}_{2}(\mathrm{~g})+2 \mathrm{Cl}_{2}(\mathrm{~g}) \uparrow
\end{gathered}
$$

The overall reaction is

$$
2 \mathrm{MgCl}_{2}+3 \mathrm{~B}_{2} \mathrm{O}_{3} \longrightarrow \mathrm{MgB}_{6}+\mathrm{MgO}+4 \mathrm{O}_{2}+2 \mathrm{Cl}_{2}(\mathrm{~g}) \uparrow
$$

Trace amount of the unreacted intermediate $\mathrm{MgO}$ was present in the synthesized compound as $0.6 \%$ and the remaining $99.4 \%$ was $\mathrm{MgB}_{6}$ as depicted from XRD pattern.

The XPS spectrum for B 1s is shown in Figure 4(a). The higher binding energy value for B 1s exists at $198.6 \mathrm{eV}$. This reflects contributions from both trigonal $\mathrm{BO}_{3}$ and tetrahedral $\mathrm{BO}_{4}$ groups. The electron transfer would come from trigonal $\mathrm{B}$ 1s to $\mathrm{B}-\mathrm{O} \sigma^{*}$ orbital and from the unfilled tetrahedral B $2 \mathrm{p}$ orbital to $\mathrm{B}-\mathrm{O} \sigma^{*}[25,26]$. This $\mathrm{B} 1 s \rightarrow \sigma^{*}$ resonance as expected for $\mathrm{sp}^{2}$-bonded boron incorporated in the crystal [27]. Figure 4(b) shows the $\mathrm{Mg}$ 1s spectra for $\mathrm{MgB}_{6}$ at $1314 \mathrm{eV}$ revealed that the auger spectral distribution over an extruded energy range far from the threshold; there is an extra energy for $\mathrm{Mg}$ rich compound [28]. Figure 4(c) shows the $\mathrm{O} 1 \mathrm{~s}$ spectrum for $\mathrm{MgB}_{6}$ existing at $544 \mathrm{eV}$. This may be due to the core-hole Rydberg states containing $\mathrm{O} 1 \mathrm{~s} \rightarrow \sigma^{*}$ resonance $[29,30]$. Figure $4(\mathrm{~d})$ shows $\mathrm{C} 1 \mathrm{~s}$ spectrum at $296 \mathrm{eV}$ and reveals energy transitions between a carbon core level and an antibonding $\pi^{*}$ molecular orbital [31]. The surface is contaminated due to exposure to air during the processing of the sample.

The $\mathrm{Mg}^{2+}$ cations in $\mathrm{MgB}_{6}$ complex species have $\mathrm{C}_{6 v}$ pyramidal structures interacting with a planar hexagonal $\mathrm{B}_{6}{ }^{2-}$ dianion. The bonding between these two may be due the electrostatic attraction [12].
The FTIR spectrum of $\mathrm{MgB}_{6}$ is shown in Figure 5. The $\mathrm{O}-\mathrm{H}$ stretching vibrations of water crystallization are represent at 3743 and $3413 \mathrm{~cm}^{-1}$, respectively. The absorption at $2225 \mathrm{~cm}^{-1}$ is assigned to $\mathrm{O}-\mathrm{H}$ stretching vibration of cluster of water molecules of crystallization, respectively. The characteristic peak of $\mathrm{Mg}-\mathrm{B}$ is observed at $1642 \mathrm{~cm}^{-1}$ [32]. Longitudinal optic mode frequency of $\mathrm{Mg}-\mathrm{O}$ is observed at $705 \mathrm{~cm}^{-1}$; this $\mathrm{MgO}$ as impurity phases is also observed in the XRD pattern. The bending vibration for $\mathrm{MgB}_{6}$ is observed at $437 \mathrm{~cm}^{-1}$. The bending mode of $\mathrm{Mg}-\mathrm{B}$ of $\mathrm{BO}_{4}$ anion is assigned to $499 \mathrm{~cm}^{-1}$. The asymmetric stretching vibration of $\mathrm{Mg}-\mathrm{B}$ of $\mathrm{BO}_{4}$ anion is observed at $1021 \mathrm{~cm}^{-1}$. The asymmetric stretching vibration of $\mathrm{B}-\mathrm{O}$ bond of trigonal $\mathrm{BO}_{3}$ units is observed at $1367 \mathrm{~cm}^{-1}$. The frequencies observed in the spectrum are in good agreement with the reported values $[33,34]$.

The SEM image of the sample is shown in Figure 6. The microstructure indicates that the particle diameters are in the range $4-8 \mu \mathrm{m}$. From the microstructure, the molten regions are clearly visible, which give the clear indication of $\mathrm{MgB}_{6}$ formation. The white regions in SEM represent the impurity phase $\mathrm{MgO}$ present in the sample [35, 36]. The present study reveals the formation of $\mathrm{MgB}_{6}$ phase as cubic crystal structure.

The mechanism of hexaboride formation was proposed by many authors $[12,14-17,37-47]$. According to Li and Jin, the negative charged boron atoms and the positive charged alkaline earth metal atoms form complexes of $\mathrm{M}^{2+}$ metal cation and $\mathrm{B}_{6}{ }^{2-}$ dianion due to electrostatic attraction. They also suggested that the metal cations $\mathrm{M}^{2+}$ have definite role on stabilizing the $\mathrm{B}_{6}{ }^{2-}$ dianion [12]. Kaptay and Kuznetsov reported that the boron components are dissolved in ionic form in the melt, to form boride phase on the cathode joint with metal cations [37]. Jose et al. reported the "unstable stoichiometric way" for the deposition of Barium hexaboride [14]. We reported earlier that the electrolytically dissociated metal and $\mathrm{B}$ ions deposit on the cathode as $\mathrm{CeB}_{6}$ and $\mathrm{SmB}_{6}$, respectively $[15,16]$. We also reported in our earlier study on $\mathrm{CaB}_{6}$ that the calcium and boron are reduced at the cathode to form submicron sized crystals [17]. As reported by Chen et al. [38], the formation of $\mathrm{MgB}_{6}$ at $900^{\circ} \mathrm{C}$ as one of the secondary phases along with $\mathrm{MgB}_{4}$ due the volatile nature of $\mathrm{Mg}$ at this temperature resulted in $\mathrm{Mg}$ deficiency on in situ $\mathrm{Cu}$ doping of $\mathrm{MgB}_{2}$. The commonly accepted mechanism of boron deposition in molten salts is a singlestep three-electron electrochemical reaction [39-43]. Gloor et al. investigated the multiexciton bound state of molecules in divalent hexaborides. They proposed that the larger energy gain per one electron-hole pair decreases the semiconducting gap and produced intermediate phase. This may be the reason for the formation of intermediate phase $\mathrm{MgB}_{6}$ [44]. Li et al. described the diffusion of $\mathrm{Mg}$ vapour into boron creating a complex of $\mathrm{Mg}-\mathrm{B}$ supersaturated solution, encompassing the formation of nonequilibrium $\mathrm{MgB}_{6}$ [45]. Lee et al. and J.Q. Li also authenticated with S. Li [45] and postulated that the path of the reaction of supersaturated $\mathrm{Mg}-\mathrm{B}$ cluster complex via spinodal decomposition leads to the formation of hypothetical phase $\mathrm{MgB}_{6}[46,47]$. 


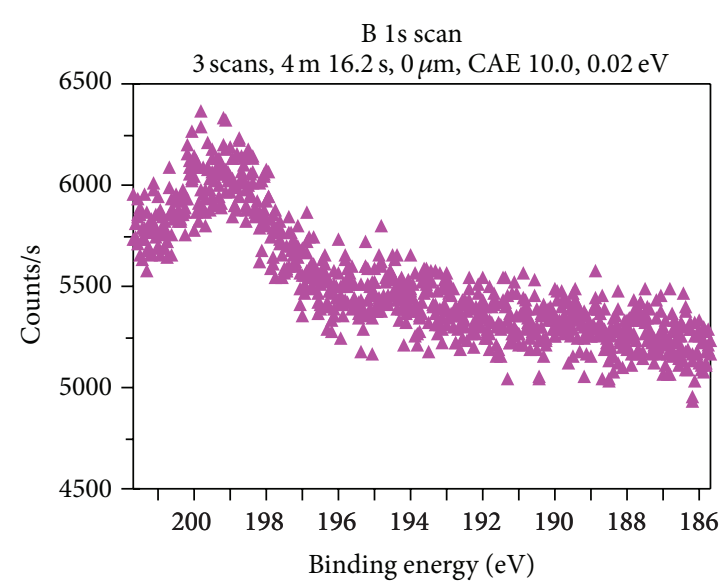

(a)

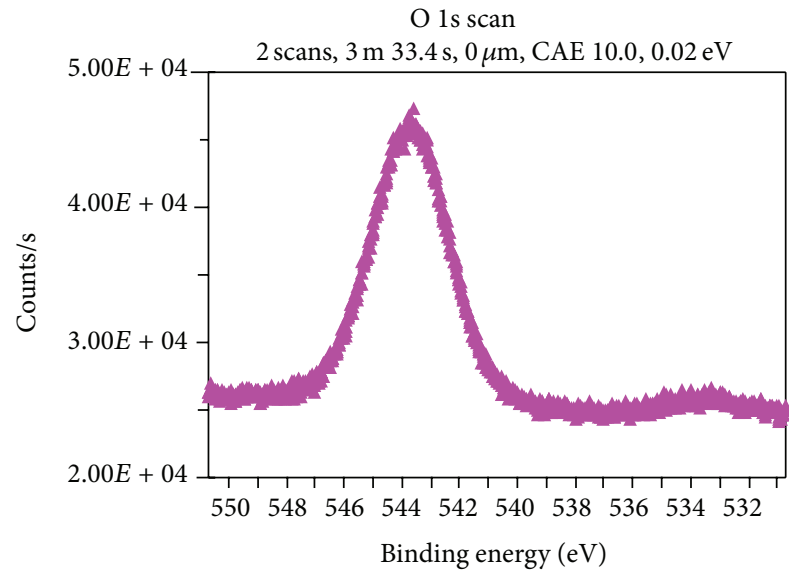

(c)

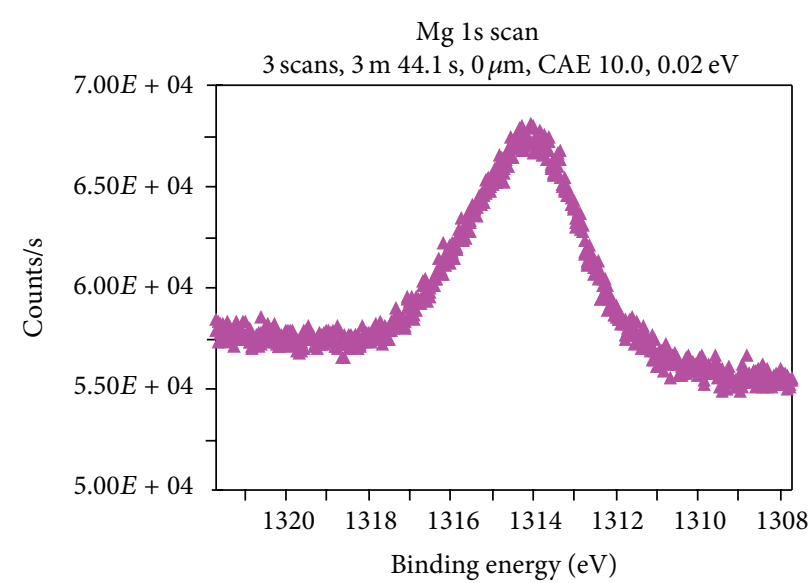

(b)

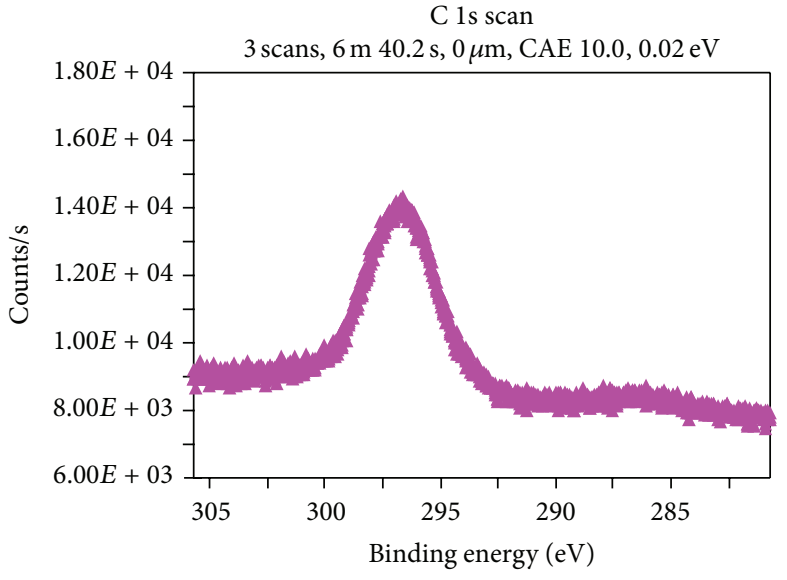

(d)

FIgURE 4: XPS spectra for (a) B 1s, (b) Mg 1s, (c) O 1s, and (d) C 1s.

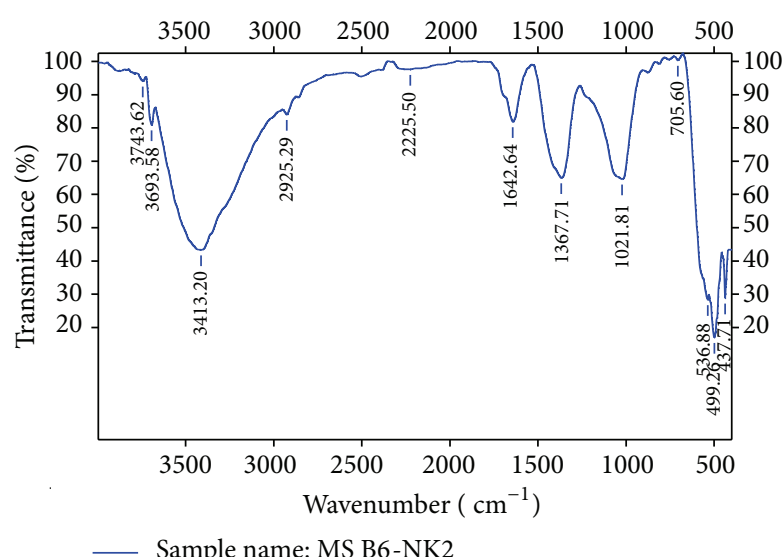

Figure 5: FTIR spectrum of $\mathrm{MgB}_{6}$.

\section{Conclusion}

In summary, the electrochemical synthesis of hypothetical magnesium hexaboride by molten salt technology is presented. Various mechanisms for the formation of magnesium

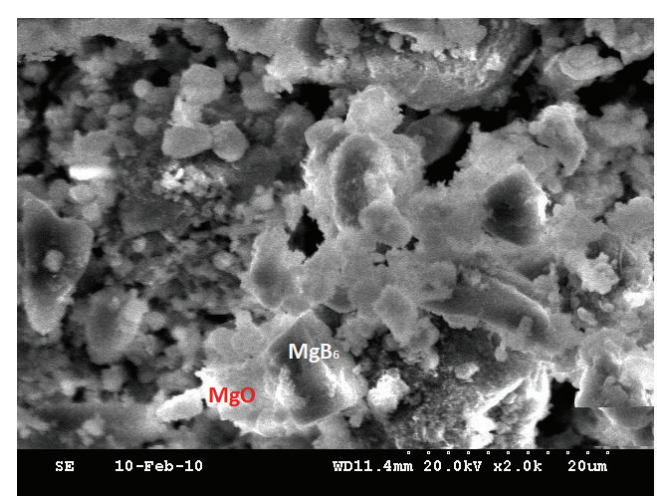

Figure 6: SEM image of $\mathrm{MgB}_{6}$.

hexaboride are discussed. It is believed that the supersaturated $\mathrm{MgB}_{6}$ cluster complex is postulated for the metastable magnesium hexaboride compound. Further experimental evidence is more needed to explore the thermodynamically unstable magnesium hexaboride. 


\section{Conflict of Interests}

The authors declare that there is no conflict of interests regarding the publication of this paper.

\section{Acknowledgments}

The authors would like to thank the Director of CSIRCECRI for his keen interest and encouragement and staff of EMP Division for their support. S. Angappan acknowledges the Council of Scientific and Industrial Research (CSIR), India, for providing the financial assistant to the project EMPOWER (OLP 0060).

\section{References}

[1] K. Segawa, A. Tomita, K. Iwashita, M. Kasaya, T. Suzuki, and S. Kunii, "Electronic and magnetic properties of heavy rare-earth hexaboride single crystals," Journal of Magnetism and Magnetic Materials, vol. 104-107, no. 2, pp. 1233-1234, 1992.

[2] C. L. Perkins, M. Trenary, T. Tanaka, and S. Otani, "X-ray photoelectron spectroscopy investigation of the initial oxygen adsorption sites on the LaB6(100) surface," Surface Science, vol. 423, no. 1, pp. L222-L228, 1999.

[3] C. Chen, W. Zhou, and L. Zhang, "Oriented structure and crystallography of directionally solidified LaB6-ZrB2 eutectic," Journal of the American Ceramic Society, vol. 81, no. 1, pp. 237240, 1998.

[4] S.-Q. Zheng, Z.-D. Zou, G.H. Min, H. Yu, J. Han, and W. Wang, "Synthesis of strontium hexaboride powder by the reaction of strontium carbonate with boron carbide and carbon," Journal of Materials Science Letters, vol. 21, no. 4, pp. 313-315, 2002.

[5] G. Kaptay, I. Sytchev, M. S. Yaghmaee, A. Kovacs, E. Cserta, and M. Ark, in Proceedings of the 6th International Symposium on Molten Salt Chemistry and Technology, p. 168, Shanghai, China, 2001.

[6] T. Y. Kosolapova, Ed., Preparation and Application of Refractory Compounds, Metallurgiya, Moscow, Russia, 1986.

[7] T. I. Serebryakova, V. A. Neronov, and P. D. Peshev, High Temperature Borides, Metallurgiya, Chelyabinsk, Russia, 1991.

[8] T. A. Serebryakova, "Classification of borides," Journal of the Less-Common Metals, vol. 67, no. 2, pp. 499-503, 1979.

[9] L. Markowsky, Y. Kondrashevsky, and G. Kaputovskaya, “The composition and the chemical properties of magnesium borides," Zhurnal Organicheskoi Khimii, vol. 25, p. 433, 1955.

[10] P. Duhart, "The borides of magnesium and aluminium," Annali di Chimica, vol. 7, pp. 339-365, 1962.

[11] G. V. Samsonov, T. I. Serebriakova, and V. A. Neronov, Borides, Atomizdat, Moscow, Russia, 1975 (Russian).

[12] Q. S. Li and Q. Jin, "Theoretical study on the aromaticity of the pyramidal $\mathrm{MB}_{6}(\mathrm{M}=\mathrm{Be}, \mathrm{Mg}, \mathrm{Ca}$, and $\mathrm{Sr})$ clusters," The Journal of Physical Chemistry A, vol. 107, no. 39, pp. 7869-7873, 2003.

[13] G. K. Moiseev and A. L. Ivanovskii, "Thermodynamic properties and thermal stability of magnesium borides," Inorganic Materials, vol. 41, no. 10, pp. 1061-1066, 2005.

[14] T. P. Jose, L. Sundar, L. J. Berchmans, A. Visuvasam, and S. Angappan, "Electrochemical synthesis and characterization of BaB6 from molten melt," Journal of Mining and Metallurgy B: Metallurgy, vol. 45, no. 1, pp. 101-109, 2009.
[15] K. Amalajyothi, L. J. Berchmans, S. Angappan, and A. Visuvasam, "Electrosynthesis of cerium hexaboride by the molten salt technique," Journal of Crystal Growth, vol. 310, no. 14, pp. 3376-3379, 2008.

[16] L. J. Berchmans, A. Visuvasam, S. Angappan, C. Subramanian, and A. K. Suri, "Electrosynthesis of samarium hexaboride using tetra borate melt," Ionics, vol. 16, no. 9, pp. 833-838, 2010.

[17] S. Angappan, M. Helan, A. Visuvasam, L. J. Berchmans, and V. Ananth, "Electrolytic preparation of $\mathrm{CaB}_{6}$ by molten salt technique," Ionics, vol. 17, no. 6, pp. 527-533, 2011.

[18] I. Popov, N. Baadji, and S. Sanvito, "Magnetism and antiferroelectricity in $\mathrm{MgB}_{6}$," Physical Review Letters, vol. 108, no. 10, Article ID 107205, 2012.

[19] S. V. Okatov, A. L. Ivanovskii, Yu. E. Medvedeva, and N. I. Medvedeva, "The electronic band structures of superconducting $\mathrm{MgB}_{2}$ and related borides $\mathrm{CaB}_{2}, \mathrm{MgB}_{6}$ and $\mathrm{CaB}_{6}$," Physica Status Solidi B, vol. 225, pp. R3-R5, 2001.

[20] A. L. Ivanovskii, "Superconducting MgB2 and related compounds: synthesis, properties and electronic structure," Russian Chemical Reviews, vol. 70, pp. 717-734, 2001.

[21] V. G. Pol, S. V. Pol, I. Felner, and A. Gedanken, "Critical current density in the $\mathrm{MgB}_{2}$ nanoparticles prepared under autogenic pressure at elevated temperature," Chemical Physics Letters, vol. 433, no. 1-3, pp. 115-119, 2006.

[22] M. Zhang, X. Wang, X. Zhang et al., "Direct low-temperature synthesis of RB6 ( $\mathrm{R}=\mathrm{Ce}, \mathrm{Pr}, \mathrm{Nd})$ nanocubes and nanoparticles," Journal of Solid State Chemistry, vol. 182, no. 11, pp. 3098-3104, 2009.

[23] P. Peshev, "A thermodynamic analysis of lanthanum hexaboride crystal preparation from aluminum flux with the use of compound precursors," Journal of Solid State Chemistry, vol. 133, no. 1, pp. 237-242, 1997.

[24] J. Ma, Y. Du, M. Wu et al., "A simple inorganic-solvent-thermal route to nanocrystalline niobium diboride," Journal of Alloys and Compounds, vol. 468, no. 1-2, pp. 473-476, 2009.

[25] A. M. Duffin, C. P. Schwartz, A. H. England, J. S. Uejio, D. Prendergast, and R. J. Saykally, " $p \mathrm{H}$-dependent $\mathrm{x}$-ray absorption spectra of aqueous boron oxides," Journal of Chemical Physics, vol. 134, no. 15, Article ID 154503, 2011.

[26] M. E. Fleet and S. Muthupari, "Boron K-edge XANES of borate and borosilicate minerals," American Mineralogist, vol. 85, no. 7-8, pp. 1009-1021, 2000.

[27] J. L. Blackburn, Y. Yan, C. Engtrakul et al., "Synthesis and characterization of boron-doped single-wall carbon nanotubes produced by the laser vaporization technique," Chemistry of Materials, vol. 18, no. 10, pp. 2558-2566, 2006.

[28] S. Altieri, L. H. Tjeng, F. C. Voogt, T. Hibma, O. Rogojanu, and G. A. Sawatzky, "Charge fluctuations and image potential at oxide-metal interfaces," Physical Review B, vol. 66, no. 15, Article ID 155432, pp. 1554321-1554326, 2002.

[29] S. Sorensen, T. Tanaka, R. Feifel et al., "Application of an atomic relaxation model for the interpretation of O1s to Rydberg excited Auger electron spectra of molecular oxygen," Chemical Physics Letters, vol. 398, no. 1-3, pp. 168-174, 2004.

[30] R. Feifel, T. Tanaka, M. Kitajima et al., "Probing the valence character of $\mathrm{O} 1 s \rightarrow$ Rydberg excited $\mathrm{O} 2$ by participator Auger decay measurements and partial ion yield spectroscopy following x-ray absorption," The Journal of Chemical Physics, vol. 126, Article ID 174304, 2007.

[31] A. Talapatra, S. K. Bandyopadhyay, P. Sen, P. Barat, S. Mukherjee, and M. Mukherjee, "X-ray photoelectron spectroscopy 
studies of $\mathrm{MgB}_{2}$ for valence state of Mg," Physica C: Superconductivity, vol. 419, no. 3-4, pp. 141-147, 2005.

[32] S. N. Kumar, S. Das, C. Bernhard, and G. D. Varma, "Effect of graphene oxide doping on superconducting properties of bulk $\mathrm{MgB}_{2}$," Superconductor Science and Technology, vol. 26, no. 9, Article ID 095008, 2013.

[33] K. Nakamato, Infrared and Raman Spectra of Inorganic and Coordination Compounds, John Wiley, New York, NY, USA, 5th edition, 1977.

[34] S. D. Ross, Inorganic Infrared and Raman Spectra, McGraw Hill, London, UK, 1972.

[35] X. Chen, T. Xia, M. Wang, W. Zhao, and T. Liu, "Microstructural transformation during combustion synthesis of MgB2 superconductor," Physica C: Superconductivity and its Applications, vol. 454, no. 1-2, pp. 38-42, 2007.

[36] R. G. Abhilash Kumar, K. Vinod, R. P. Aloysius, and U. Syamaprasad, "A simple and inexpensive method for rapid synthesis of $\mathrm{MgB}_{2}$ superconductor," Materials Letters, vol. 60, no. 28, pp. 3328-3331, 2006.

[37] G. Kaptay and S. A. Kuznetsov, "Electrochemical synthesis of refractory borides from molten salts-review paper," Plasmas \& Ions, vol. 2, pp. 45-56, 1999.

[38] S. K. Chen, M. Majoros, J. L. MacManus-Driscoll, and B. A. Glowacki, "In situ and ex situ Cu doping of $\mathrm{MgB}_{2}$," Physica $\mathrm{C}$ : Superconductivity and its Applications, vol. 418, no. 3-4, pp. 99106, 2005.

[39] R. Thompson, "The chemistry of metal borides \& related compounds," in Progress in Boron Chemistry, R. J. Brotherton and H. Steinberg, Eds., vol. 2, pp. 178-230, Pergamon Press, Oxford, UK, 1970.

[40] P. R. Davis, M. A. Gesley, G. A. Schwind, L. W. Swanson, and J. J. Hutta, "Comparison of thermionic cathode parameters of low index single crystal faces of LaB6, CeB6 and PrB6," Applied Surface Science, vol. 37, no. 4, pp. 381-394, 1989.

[41] S. V. Meschel and O. J. Kleppa, "Standard enthalpies of formation of some borides of Ce, Pr, Nd and Gd by high-temperature reaction calorimetry," Journal of Alloys and Compounds, vol. 226, no. 1-2, pp. 243-247, 1995.

[42] G. Balakrishnan, M. R. Lees, and D. M. K. Paul, "Growth of large single crystals of rare earth hexaborides," Journal of Crystal Growth, vol. 256, no. 1-2, pp. 206-209, 2003.

[43] C. Y. Zou, Y. M. Zhao, and J. Q. Xu, "Synthesis of singlecrystalline CeB6 nanowires," Journal of Crystal Growth, vol. 291, no. 1, pp. 112-116, 2006.

[44] T. A. Gloor, M. E. Zhitomirsky, and T. M. Rice, "Multiexciton molecules in the hexaborides," European Physical Journal B, vol. 21, no. 4, pp. 491-497, 2001.

[45] S. Li, O. Prabhakar, T. T. Tan et al., "Intrinsic nanostructural domains: possible origin of weaklinkless superconductivity in the quenched reaction product of $\mathrm{Mg}$ and amorphous B," Applied Physics Letters, vol. 81, no. 5, pp. 874-876, 2002.

[46] S. Lee, H. Mori, T. Masui, Y. Eltsev, A. Yamamoto, and S. Tajima, "Growth, structure analysis and anisotropic superconducting properties of MgB2 single crystals," Journal of the Physical Society of Japan, vol. 70, no. 8, pp. 2255-2258, 2001.

[47] J. Q. Li, L. Li, Y. Q. Zhou, Z. A. Ren, G. C. Che, and Z. X. Zhao, "Structural features, stacking faults, and grain boundaries in MgB2 superconducting materials," http://arxiv.org/abs/condmat/0104350. 

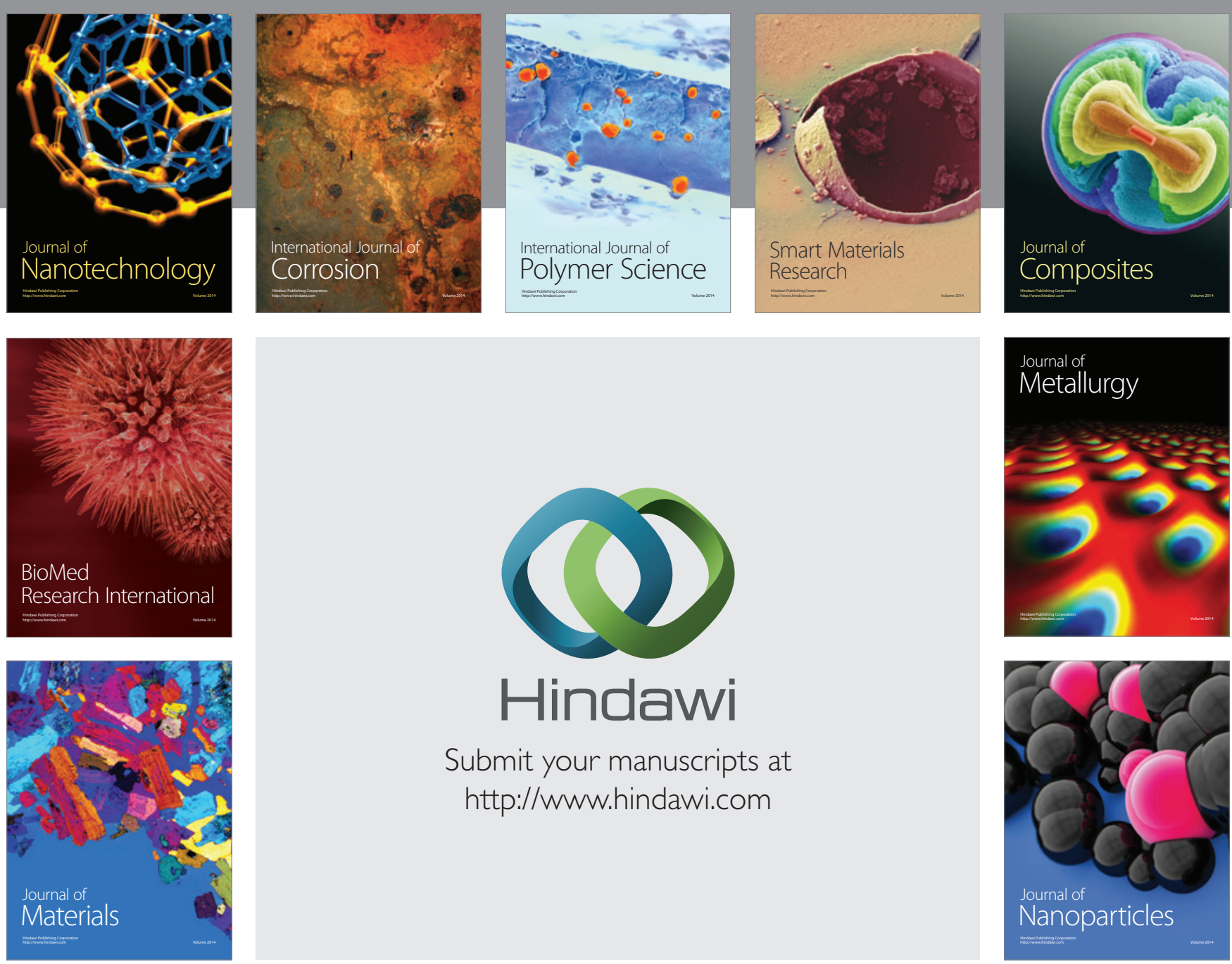

Submit your manuscripts at http://www.hindawi.com
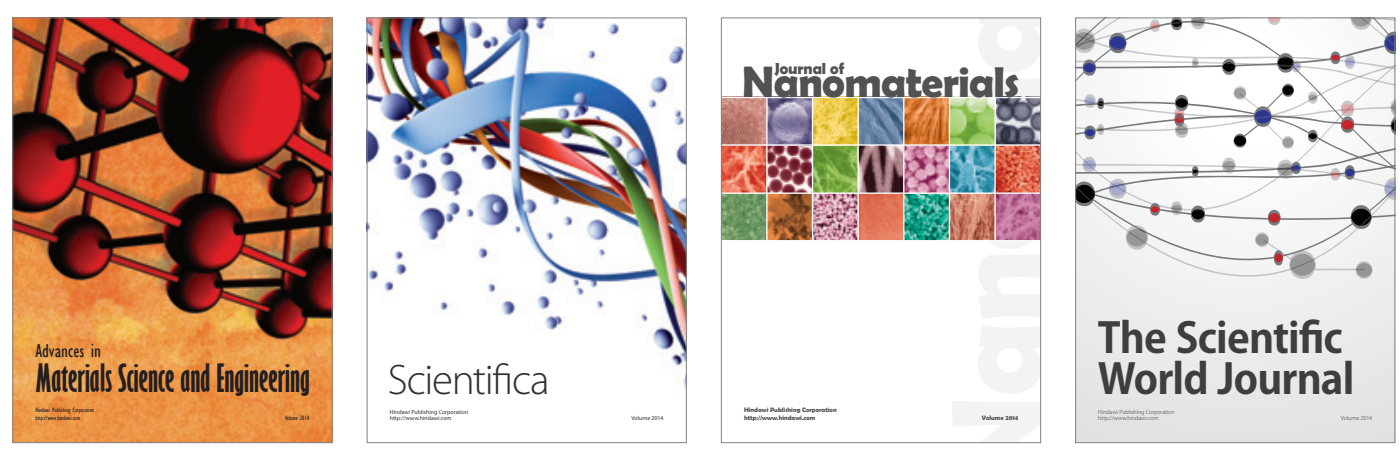

\section{The Scientific World Journal}
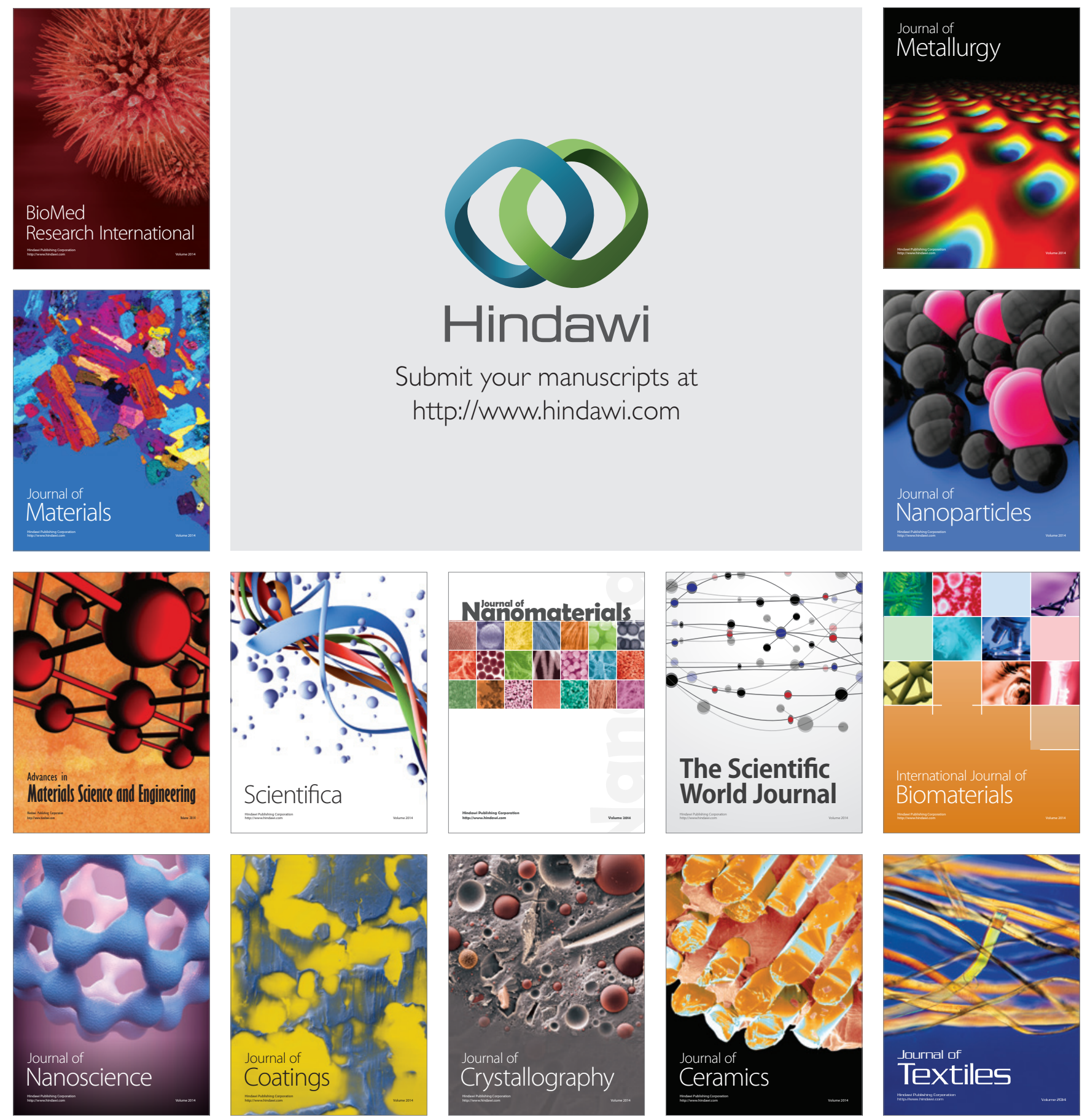